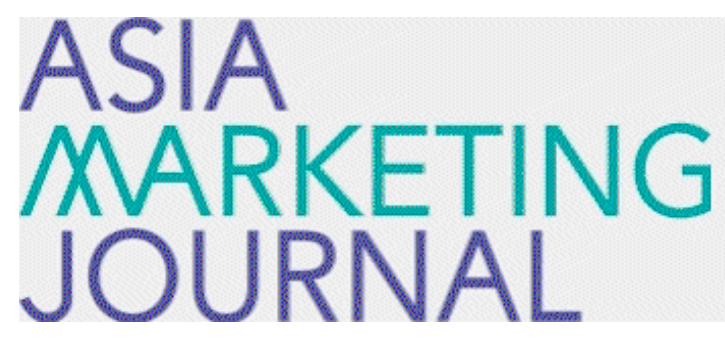

ASIA MARKETING JOURNAL

Volume 16 | Issue 1

Article 12

4-30-2014

\title{
Hyundai Motor's Global Marketing Strategy
}

Woo Seong Kang

Young Chan Kim

Chang Jo Yoo

Follow this and additional works at: https://amj.kma.re.kr/journal

Part of the Marketing Commons

\section{Recommended Citation}

Kang, Woo Seong; Kim, Young Chan; and Yoo, Chang Jo (2014) "Hyundai Motor's Global Marketing Strategy," Asia Marketing Journal: Vol. 16 : Iss. 1 , Article 12.

Available at: https://doi.org/10.53728/2765-6500.1535

This Article is brought to you for free and open access by Asia Marketing Journal. It has been accepted for inclusion in Asia Marketing Journal by an authorized editor of Asia Marketing Journal. 


\section{Hyundai Motor's Global Marketing Strategy: "New Thinking. New Possibilities."}

Wooseong Kang*

Youngchan Kim**

Changjo Yoo ${ }^{* * *}$

The automotive industry plays a significant role in the global economy. One of the reasons is that this industry compasses every aspects of the value chain - from raw materials to design and development, manufacturing, sales and services, and even disposal. Thus, the industry needs significant upfront capital investment and requires years of $R \& D$ and market development. As a result, this industry is dominated by a handful of global players and it is not easy for a new entrant to enter this industry. Furthermore, success is even more difficult to achieve. How did Hyundai Motor make it in this tough marketplace? Can it continue against all odds?

The CAGR for last 5 years is $12 \%$ and it stands at 6 th in the world. Compared to other global brands, Hyundai has geographically well-balanced sales portfolio. The quality improvement is outstanding. The brand performance follows these quality and sales improvements. Yet, the global competition is ever intensifying. Now, it is the time to step up once more. The next strategic goal needs fundamental shift toward brand and marketing-focus.

In constructing global marketing strategy, Hyundai Motor's vision is "Lifetime partner in mobility and beyond" and its goal is global top 3 brand by year 2015 through modern premium brand image and selling 5 million vehicles. The target brand positioning of Hyundai Motor is the leading position in premium dimension and stylish/modern dimension. The global brand strategy framework is based on the brand direction of "Modern Premium" and is designed to deliver core brand identity (i.e., Simple, Creative, Caring) to customers. In order to manage brand performance, Hyundai's marketing platform also includes marketing performance management, brand performance management, and market driven organization.

From this diagnosis, Hyundai Motor is well posed to build a strong brand. Nevertheless, there are still challenges ahead from consumer, technology, competitor, and macro-environment perspectives. To overcome these threats, the bases of competition for all successful automotive brands are various

\footnotetext{
* Associate Professor, Dongguk University-Seoul(wskang@dongguk.edu)

** Professor, Yonsei University(youngkim@yonsei.ac.kr)

*** Professor, Dongguk University-Seoul(yoo@dongguk.edu)
} 
differentiation factors, including technology, performance, value proposition, or heritage. Hyundai Motor is well prepared so far. However, it is not tested against time yet whether Hyundai can overcome these unforeseeable major threats. Hyundai is trying to find the solution from a strong brand, while believing in "New Thinking. New Possibilities."

Key words: Hyundai Motors, Automotive industry, Brand management, Global marketing strategy

\section{Introduction}

Entering $21^{\text {st }}$ century, automotive industry experts used to say that "In the near future, only top 10 global companies will survive!" Or, some even said, "Only top 6 will be there." They offered various rationales and, of course, sounded credible. In the lists of those top 10 or top 6 companies, we could not find Hyundai Motor. After 10 years later, Hyundai Motor Group ranks top $5^{\text {th }}$ in the global automotive market and continues to grow.

The automotive industry plays a significant role in the global economy. One of the reasons is that this industry compasses every aspects of the value chain - from raw materials to design and development, manufacturing, sales and services, and even disposal. Thus, the industry needs significant upfront capital investment and requires years of $R \& D$ and market development. As a result, this industry is dominated by a handful of global players. For these reasons, it is not easy for a new entrant to enter this industry. Furthermore, success is even more difficult to achieve. How did Hyundai Motors make it in this tough marketplace? Can it continue against all odds?

\section{The History}

The current status of Hyundai Motor is well demonstrated by sales, product quality, and brand equity. The cumulative aggregate growth rate (CAGR) of Hyundai Motor for last 5 years is $12 \%$ and it stands at 6th among global automotive companies (5th with Kia Motor). (see Figure 1)

Hyundai achieved this sales growth not only from the domestic market but also from wide variety of global markets, including North America, Europe, China, and India (see Figure 2). Compared to other global brands, Hyundai has geographically well-balanced sales portfolio (c.f., Volkswagen is focusing on Europe and China markets; GM is focusing on North America market). This diversification helps to resist any region-specific challenges. 
〈Figure 1〉 Sales of Hyundai Motors

CAGR

$12.2 \%$

(Unit: million)

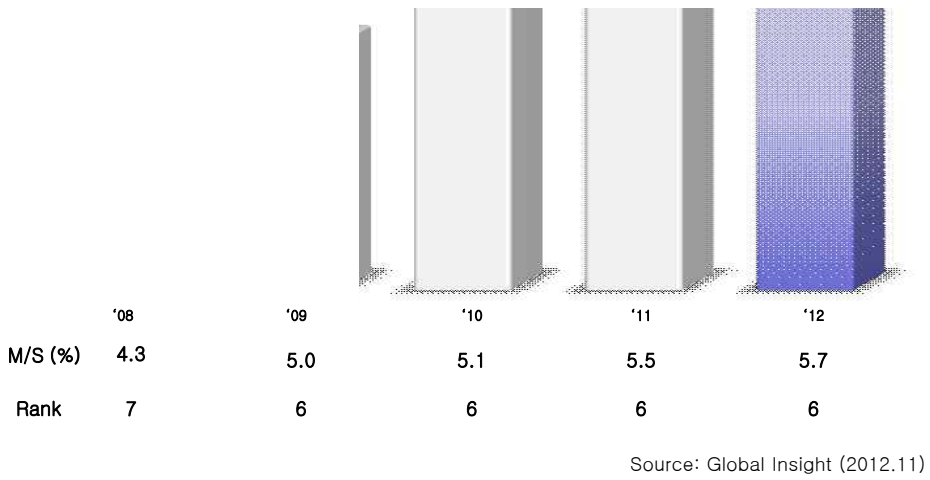

〈Figure 2〉 Diversification of Hyundai Motors in Sales

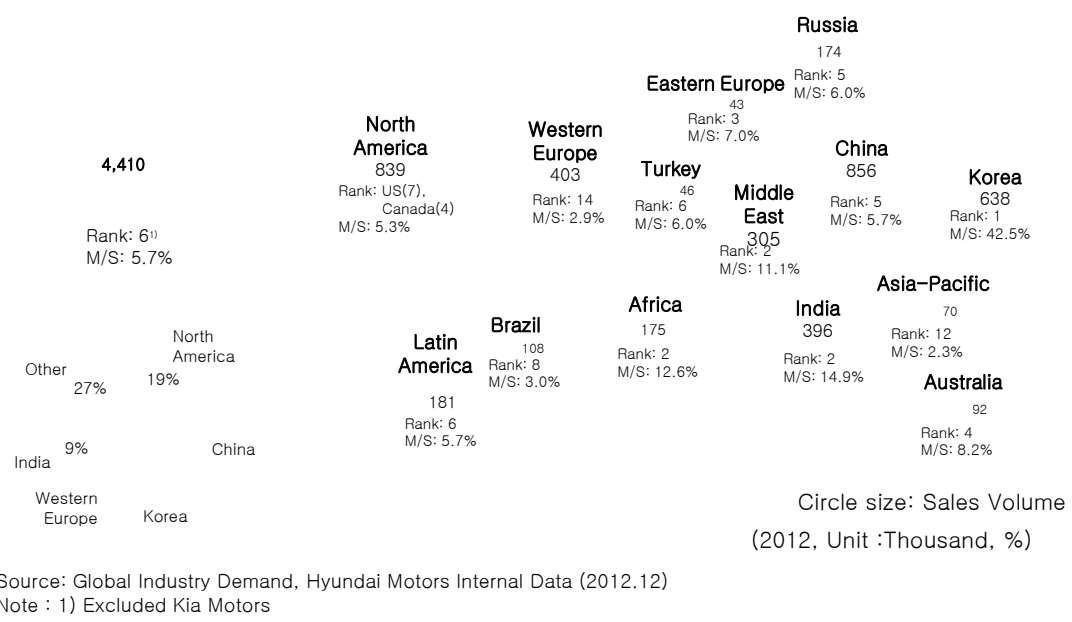

The quality improvement is the starting point of Hyundai's rapid rebound. And, its improvement is outstanding. A decade ago, Hyundai's initial quality and dependability have been way below industry average. After launching quality management program, they continue to im- prove ever since (see Figure 3). Now the vehicle quality is on a par with industry average. Note that Hyundai even temporarily surpassed Toyota, the industry leader in quality, with respect to initial quality. The vehicle quality is the core element of competitive advantage in 
〈Figure 3〉 Quality Improvement over last 10 years

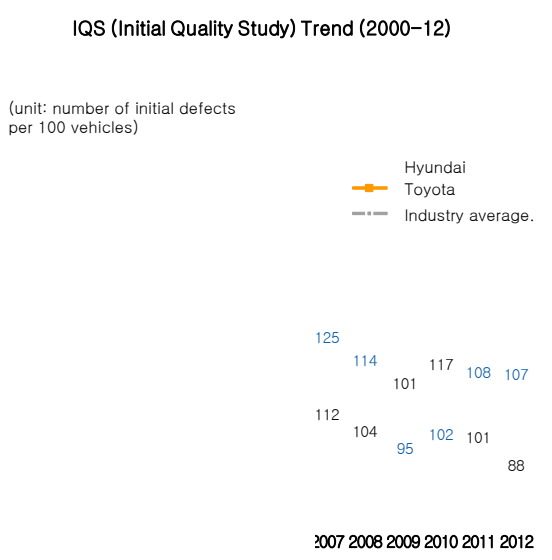

IQS (Initial Quality Study) Trend (2000-12)

200720082009201020112012
VDS (Vehicle Dependability Survey) Trend (2000-12)

(unit: number of durable defects per
100 vehicles)

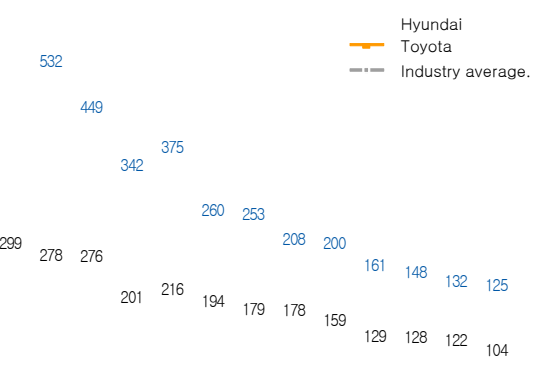

2000200120022003200420052006200720082009201020112012

Source: J.D. Powers

53rd in rankings, improved by 8 steps, and Hyundai boasts the fastest rising top brand in automotive sector.

As a result, not surprisingly, the world presses appreciate the achievement and global customers continue to recognize and award the various Hyundai vehicle models. report, in 2012, the brand value of Hyundai
Motors is 7.5 Billion $\$$ (see Figure 4). This is

〈Figure 4〉 Brand Value

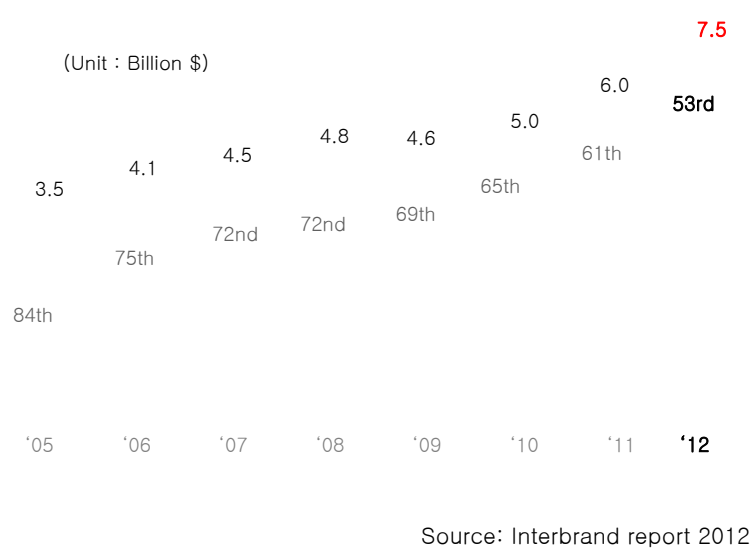




\section{Need for Brand Management}

Hyundai Motors achieved successful quality improvement and it is about to complete the full-fledged global production and management system. Now, it is the time to step up once more after the annual production/sales of 4.5 million vehicles. The strategic direction should be more than quality and sales orientation. The next strategic goal needs fundamental shift toward brand and marketing-focus.

The global competition is ever intensifying. When we look at the industry's competitive situation, there are continuing over supply and intensified competition especially in volume segment. Luxury brands are entering into the segment with small cars and low-end brands are penetrating with low price strategy. These result in significant over-supply, thereby leading to intense competition. In addition, from consumer perspective, customer tastes are diversifying due to the experiential/emotional consumption and desire for differentiation. These increased competitive intensity in automotive industry and changes in customer tastes are posing significant treats for sustainable growth of global players, including Hyundai Motor. Thus, facing these obstacles, it is necessary to create a new growth engine. Put differently, in order to maintain sustainable growth, Hyundai needed to shift the business paradigm from a good quality car manufacture to a strong brand, satisfying customer's emotional aspect. During the period of quality management and global management, "Value for Money" was good enough for sales volume increase. In fact, selling more cars has been the goal of Hyundai Motor so far. However, this is purely a growth in quantity, lacking in a strong brand image. Therefore, in order to grow with quality, Hyundai needs to pursue customer's emotional satisfaction by building a strong brand image, which helps to be loved by customers. By constructing a differentiated brand image Hyundai plans to add brand management on top of the quality and global management. This new brand direction consists of brand and marketing oriented management with market-driven organization and strong market insight/innovation (see Figure 5).

\section{Building Strong Brand}

In general, companies with a strong brand can enjoy a great deal of advantages. With successful marketing programs, which allow the brand to register a positive brand image in customer's memory, one can realize many advantages for the brand. The benefits include strong brand loyalty, less vulnerable to competitor's marketing actions and marketing crises, larger profit margin, inelastic consumer response to price increase but elastic to price decrease, and increased effectiveness of marketing communica- 


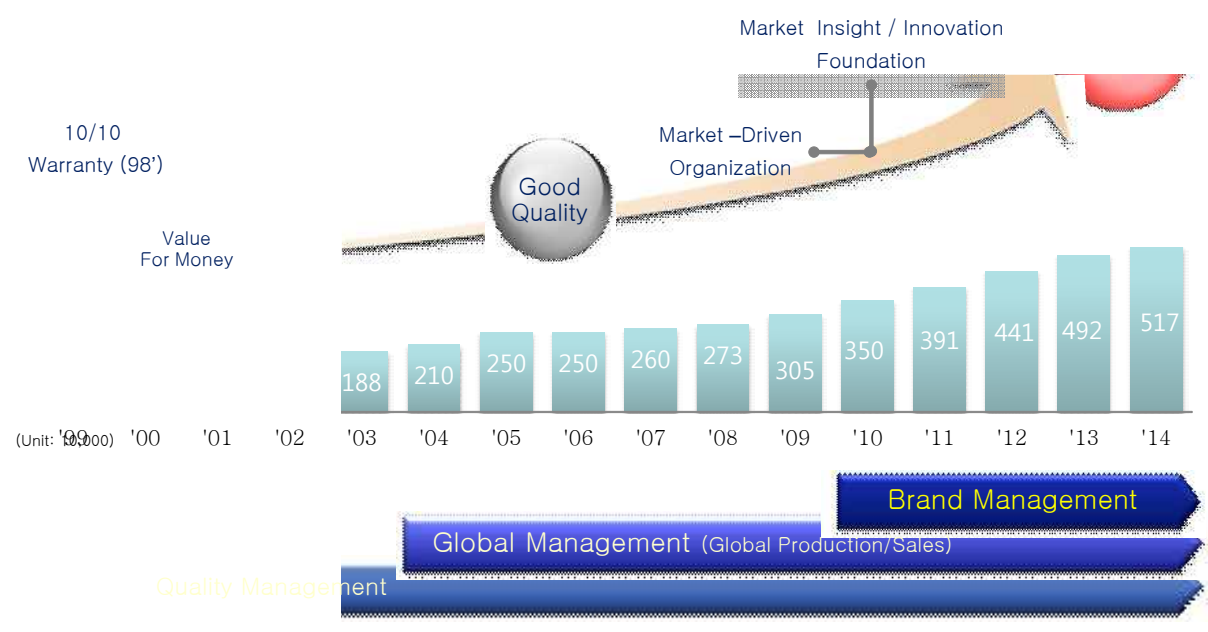

tion (Keller 2003).

Generally, building a strong brand involves

(1) Identifying and Establishing Brand Positioning,

(2) Planning and Implementing Brand Marketing

Programs, (3) Measuring and Interpreting Brand Performance, and (4) Growing and Sustaining Brand Equity (Keller 2003).

- Identifying and Establishing Brand Positioning: Building a strong brand begins with brand positioning, which can be defined as the "act of designing the company's offer and image so that it occupies a distinct and valued place in the target customer's mind". One needs to have a clear understanding of what the brand represents and how it is positioned against competitors. Basically, positioning persuades customers that a brand has advantages (i.e., points of differences) over competitors and, at the same time, that the brand can soothe any concerns about disadvantages (i.e., points of parity).

- Planning and Implementing Brand Marketing Programs: A strong brand implies that consumers are well aware of the brand and they have strong, favorable, and unique associations with the brand. Thus, one needs to design all elements of the brand and marketing programs to create high brand awareness and desired brand image. In addition, to create a strong and favorable brand association, a high consistency across brand elements is also required. That is, by delivering the same message with well integrated marketing communication, consistency can ensure the brand and marketing mix share a common core brand meaning.

- Measuring and Interpreting Brand Performance: The brand positioning strategy will be fol- 
lowed by the actual marketing program to strengthen brand associations. To implement these marketing programs, the company should measure and manage brand performance in the entire value creation process, i.e., the brand value chain. Also, to manage their brands profitably, brand managers should design a system for brand equity measurement, which provides necessary information for marketers.

- Growing and Sustaining Brand Equity: Even after establishing a strong brand, growing and expanding on brand equity can be still challenging. Sustaining brand equity asks for understanding how brand strategies should address concerns and be adjusted over time or over market segments within the context of other brands or multiple categories.

\section{Hyundai Motor's Global Marketing Strategy}

Based on these backdrops, Hyundai has been developing global marketing strategy to build a strong brand. Hyundai Motor's vision is "Lifetime partner in mobility and beyond" and its goal is global top 3 brand by year 2015 through modern premium brand image and selling 5 million vehicles. As we can see below, the target brand positioning of Hyundai Motor is the leading position in premium dimension and stylish/ modern dimension (see Figure 6).

The marketing platform for leaping into global top 3 brand is as follows. Hyundai's marketing platform consists of Plan-Do-See framework (see Figure 7). In planning, Hyundai develops global brand strategy and market insight-based regional marketing strategy. Also, by operating

〈Figure 6〉 Hyundai's Brand Target Positioning

Premium 


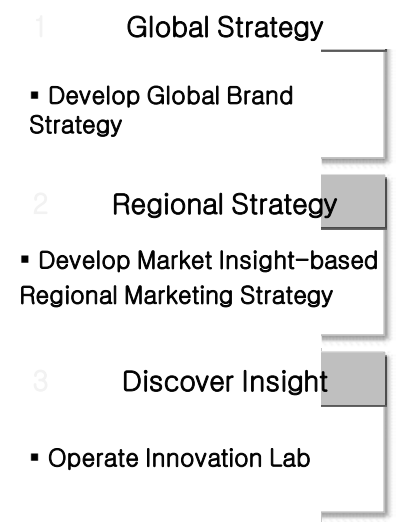

\begin{tabular}{l}
\multicolumn{1}{c|}{ Improve Brand Power } \\
\hline -Rollout Global Brand Campaign \\
-Offer Premium Touch point \\
\hline 2 Support Product Marketing \\
\hline - Strengthen Premium Product \\
Marketing \\
\hline 3 Strengthen Customer Base \\
\hline - Youth Marketing \& Brand \\
Collaboration \\
- Sports/CSR/Culture Marketing \\
\hline
\end{tabular}

Marketing Performance

- Marketing Performance

Management System

2 Brand Performance

- Brand Performance

Management (BPM) System

3 Market-driven Organization

- Global Marketing Conference

- Market Driven Company innovation lab, it discovers insights. In action stage, to improve brand power, it rollouts global brand campaign and offers premium touch points. To support product marketing, it also strengthens premium product marketing. To strengthen customer base, youth marketing/ brand collaboration/sports/CSR/culture marketing initiatives are implemented. In performance management stage, marketing performance management system and brand performance management systems are in place. Also, it builds market-driven organization.

Hyundai Motor's new global brand strategy framework is based on the brand direction of "Modern Premium" and is designed to deliver core brand identity (i.e., Simple, Creative, Caring) to customers (see Figure 8).

Hyundai Motor's brand direction (brand identity) is "Modern Premium", that is, offering new experience and value, beyond the expectation by current customers, to more customers with Hyundai's unique approach. Still a volume car manufacturer, yet, Hyundai wants to be a beloved brand which provides customers with pride and moving experience by delivering unique premium experience and value. That is, modern premium implies delivering differentiated emotion and experience at reasonable price. It is differentiated from luxury premium brands based on heritage/art, targeting a small segment with high prices, as well as from low-end volume manufactures based on functionality, targeting a wider population with low prices. The main target is the individualized crowds (i.e., customers' desire for differentiation), the delivered value is Anew value with reasonable price, and the delivery approach is customer experienceoriented marketing communications in every directions.

In order to achieve this brand identity, from 

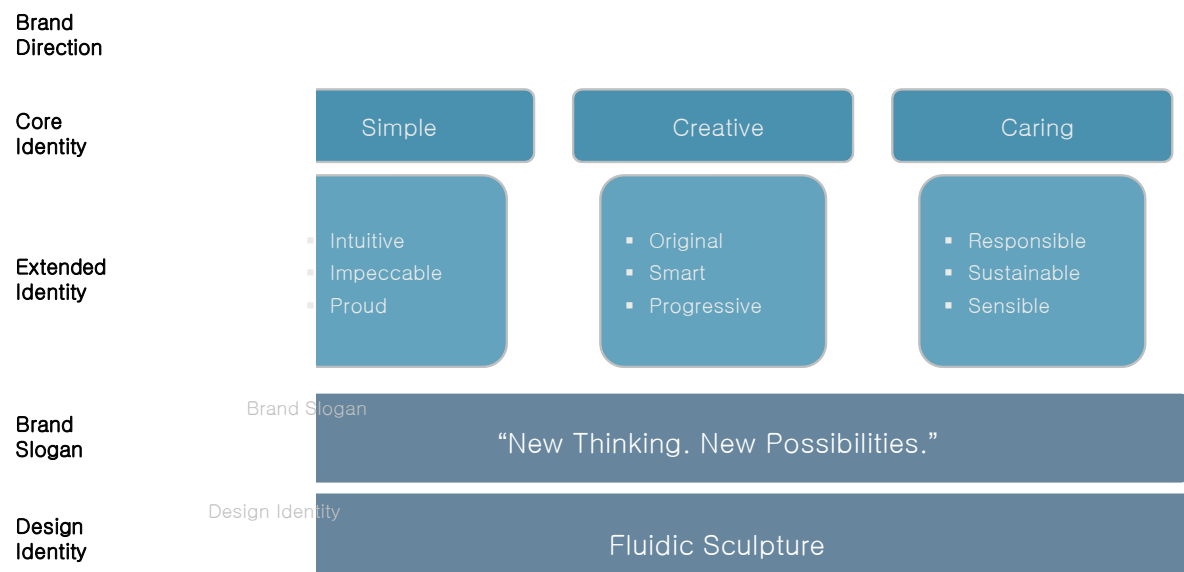

Brand

Slogan

\section{"New Thinking. New Possibilities."}

\section{Fluidic Sculpture}

emotion, thinking, and being perspectives, the core identity delivers three core values: Simple, Creative, Caring. These values consist of three sub-values, respectively (see Figure 9).

The interpretations of these core values are as follows:

- Simple ('the most modern way'): What the current customers want is not complex nor fancy products. Rather, they want intuitive and simple ones. The impeccable simplicity offers one step higher pride.

- Creative ('Hyundai Motor's unique way'): With Hyundai Motor's unique originality, Hyundai pursues progressive creativity into the future via smart approach.

- Caring ("offering anew experience and value'): Hyundai fulfills customer and social responsibilities, considers sustainable future, and sensibly provides customers with what they really want.

〈Figure 9〉 Brand Identity and Core Identity

Modern Premium

$$
\begin{gathered}
\text { Simple } \\
\text { Intuitive } \\
\text { Impeccable } \\
\text { Proud }
\end{gathered}
$$

Creative

Original

Progressive
Caring

Responsible

Sensible 
Then, under the brand direction of Modern Premium, the brand slogan is "New Thinking. New Possibilities." This helps to communicate with customers.

\section{Implementing Brand Strategy}

The process of implementing the brand strategy is to share brand direction, to set up brand action principles, and to develop brand RTB (Reason to Believe). Specific implementation examples are as follows:

(1) For the modern premium target image of "Simple" (Brand direction), the action principle is "Make it easy," i.e., the easier and more comfortable purchase/service experience. That is, Hyundai always thinks from customer perspective and all design, expression, and action are designed to allow customers to experience Hyundai Motor more easily and comfortably. The RTB is developing and implementing 3 visiting services (Visiting Before service, 365 days Visiting Test-drive service, Home to Home service)

(2) For the modern premium target image of "Creative" (Brand direction), the action principle is "Act Smart," i.e., becoming a smart car specialist. That is, all employees should be proud of the best automotive brand and offer unique and differ- entiated smart services to customers. The RTB is to increase branch professionalism (utilizing smart devices, progress information screen)

(3) For the modern premium target image of "Caring" (Brand direction), the action principle is "Personalized Care," i.e., $1: 1$ customization service. That is, by believing customers and the company is a family, all employees think customers as family and should offer warm consideration and delicate services. The RTB is the customer emotional satisfaction (Female drivers' campaign, Improving sales facilities, Female-only space).

In addition, in order to achieve the brand goal of modern premium more effectively, the implementation plan also includes changing customer perceptions and strengthening brand competitiveness via company-wide consistent action programs. To be specific, the product/ $R \& D /$ design areas strengthen basic capabilities through initial quality improvement, develop product \& design identities, and establish brand portfolio strategy. The marketing/communication/ publicity/CSR areas strengthen basic capabilities by coordinating strategy between corporate headquarter and local branches, deploy global brand campaign, and intensify space marketing by building brand shops. The sales/service areas strengthen basic capabilities through CSI/SSI improvement, establish global sales infrastructure 
standard (hardware), and develop global customer experience process (software). Finally, the internal process builds market driven corporate culture, innovate internal job processes, and improve employees' pride and satisfaction.

\section{Managing Brand Performance}

In order to manage brand performance, Hyundai's marketing platform includes three tasks: (1) marketing performance management, (2) brand performance management, and (3) market driven organization.

(1) Building marketing performance management system: The first task is to develop management indexes for global marketing performance management. First, this analyzes and supports the marketing performance in order to assure the company-wide market activities are under consistent goals. Second, it helps to increase the effectiveness of global marketing activities under limited resources. Third, by consistently tracking the objective management indexed and identifying potholes, it allows planning a firmlevel support direction

(2) Building brand performance management system: The second task is to develop a practical guideline (evaluation items and analysis framework) to measure brand performance. Specifically, the periodic worldwide consumer researches are conducted to diagnose brand positions of Hyundai Motor and its competitors and to manage the brand more effectively. The major research areas include brand index (e.g., initial recall, unaided recall, familiarity, preference, purchase consideration, first choice preference), brand image (e.g., emotional image, functional image), buying process (initial consideration, final consideration, final purchase, purchase barriers), and brand loyalty (intention to rebuy, brand switching, satisfaction).

(3) Constructing market-driven organization: The third task is to deploy a sustainable marketing program through market-oriented corporate culture and a shared marketing direction. Two examples are MDC and GMC. The goal of MDC (Market Driven Company) program is to facilitate market oriented organization culture in order to a most loved brand. The representative programs are MDC Special Lecture and MDC Executive On-site Seminar. MDC Special Lecture invites influential leader, famous scholars, or designers and consists of special lectures to internalize various industry insights and creative ideas. The MDC Executive On-site Seminar focuses on how to build premium image and communicate the premium image with customers by visiting global premium 
brands' headquarter, service lounge, and brand shop. The GMC (Global Marketing Conference) program is designed to share internally the long-term brand/marketing visions. The main programs include presenting brand performance evaluation and long-term vision, presenting longterm marketing strategy and core initiative, launching new cars with Hyundai's design identity, sharing and awarding global marketing/branding best practices, presenting market insight analysis, and workshops to discuss current marketing issues.

\section{Conclusion}

What makes a strong brand? First, a firm needs to understand the meaning of brand and to market right products in a right manner. This leads to a proper brand position in customers' mind as well as in the marketplace. Hyundai has a clear target brand positioning, i.e., the leading position in premium dimension and stylish/modern dimension. The brand identity of "Modern Premium" also offers new experience and value, beyond the expectation by current customers, to more customers with Hyundai's unique approach.

Second, a brand is indeed a promise and a commitment. A firm needs to deliver desired benefits to customers. In fact, Hyundai Motor's brand identity is delivered through three core values: Simple, Creative, Caring. The core values are delivered to customers by sharing brand direction, setting up brand action principles, and developing brand RTB(Reason to Believe). Third, a firm needs to employ all aspects of complementary brand elements and supporting marketing activities. Of course, creating and maintaining brand association requires continuous marketing investments. Hyundai is making significant investment not only in hardware but also in software. And, these investments continue.

Fourth, a firm needs to embrace integrated marketing communications with a consistent message. This will help build a firm foundation for brand equity, i.e., deep and broad customer awareness and strong, favorable, and unique associations. Under the brand direction of Modern Premium, the brand slogan is "New Thinking. New Possibilities." This consistent message helps to communicate with customers. In addition, the brand identity is embedded in the product identity and design identity.

Fifth, a firm needs to implement a brand management system, which will ensure proper marketing actions. Effective brand management system requires focus, discipline, creativity, and the ability to make a series of ongoing decisions in the best possible way. Hyundai Motor's marketing platform for leaping into global top3 brand is Plan(Insight \& Strategy)-Do(Action)See (Performance Management) framework. In 
order to manage brand performance, Hyundai's marketing platform includes three tasks: marketing performance management, brand performance management, and market driven organization.

From this diagnosis, Hyundai Motor is well posed to build a strong brand. Nevertheless, there are still challenges ahead (see Figure 10). From consumer perspective, customers demand both affordable price and premium value at the same time. It used to be acceptable to offer one of them. Now, these conflicting benefits need to be met. Also, as global market $\mathrm{ex}^{-}$ pands, the regional differences with respect to culture, income, or tastes loom larger. From competitor perspective, the leading brands are resurrecting from major crisis, including GM and Toyota. At the same time, the challenges from latecomers (e.g., China, India) are ever increasing. The technology evolution is demanding as well. There are more electronics in a car, which widens the competitive landscape. It asks for collaborations with electronics companies as well as competitions against them. More and more convenience and safety features are added into a car. Of course, environmentally friendly cars are inevitable. From macro-environment perspective, there are still significant demand fluctuations across vehicle segments as well as unstable demand across vehicle models. Answers to all these challenges are not clear yet. All successful automotive brands are competing against each other in the marketplace. The bases of competition are various differentiation

〈Figure 10〉 Challenges Ahead

\begin{tabular}{|c|c|}
\hline $\begin{array}{c}\text { Affordable } \\
\text { Price }\end{array}$ & $\begin{array}{l}\text { Resurrection } \\
\text { of leading brands }\end{array}$ \\
\hline Regional & Challenges from \\
\hline $\begin{array}{l}\text { Difference } \\
\text { (Culture, Income) }\end{array}$ & $\begin{array}{l}\text { latecomers } \\
\text { (China, India) }\end{array}$ \\
\hline More & Demand Fluctuation \\
\hline Electronics & across vehicle segment \\
\hline $\begin{array}{c}\text { More Convenience, } \\
\text { Safety Features }\end{array}$ & Unstable/Volatile \\
\hline $\begin{array}{c}\text { Environmentally } \\
\text { Friendly Car }\end{array}$ & Demand \\
\hline
\end{tabular}

Hyundai Motor's Global Marketing Strategy: "New Thinking. New Possibilities." 227 
factors, including technology, performance, value proposition, or heritage/art. Now, most of global players have comparable technology to produce a quality product. Investment for next generation technology is under way as well. Global production and sales systems are in place. Each brand also has developed unique product portfolio for global markets. To do this, Hyundai Motor already has a highly diversified product portfolio. Hyundai also accomplished global diversification in production and sales systems, which is much more balanced than other global competitors. These indeed helped Hyundai to overcome recent economic crises. However, from now on, it needs unique capability to overcome upcoming challenges and the risks posed by consumer, technology, and environmental changes. Many top brands have experience to overcome critical threats, including the Renault-Nissan strategic alliance and Toyota's risk management for major recalls. But, it is not tested against time yet whether Hyundai can overcome these unforeseeable major threats. Hyundai is trying to find the solution from a strong brand, while believing in "New Thinking. New Possibilities."

\section{References}

Keller, Kevin L (2008), Strategic Brand Management, $3^{\text {rd }}$ ed., Pearson, Upper Saddle River, New Jersey 